\title{
Enhancing insight discovery by balancing the focus of analytics between strategic and tactical levels
}

Received: 31st May, 2006

\section{Tim Cooper}

has a Masters degree in data analysis and has analysis experience from more than half a dozen industries in as many countries. His three years as an international communication manager at Novo Nordisk based in Denmark, gave him great experience with strategy and communications. This complements his extensive analysis experience with companies like Avis, Vodafone, VNU, CMT (now Claritas), the data-driven agency DBT (primarily working with Cyanamid across Europe), eBay and, now at Merck Sharp \& Dohme Australia.

Tim Cooper

Customer Insights Analysis

Manager

Merck Sharp \& Dohme

54-68 Ferndell Street

South Granville NSW 2142

Australia

Tel: +61 (0)2 97959525

e-mail:

Tim_Cooper@Merck.com

Web:

www.msd-australia.com.au

\begin{abstract}
An insight at a strategic level can change an industry, but most marketers/analysts are more micro-focused; insights at a tactical level are more typical and incremental advantages over competitors are the norm. Since the only real source of competitive advantage is learning faster than competitors and then implementing the learnings, deciding where to focus is crucial. The dominantly micro approach considerably limits how companies view the benefits of data and, thus, how it is used - in turn limiting how companies invest in data. When developing and supporting corporate strategy, many organisations do not realise the full potential of customer databases, nor are they integrated with other sources, such as market research or competitor intelligence.

In this paper, 'insight' and 'strategy' are defined and the importance of balancing the analysis effort appropriately between tactical and strategic levels demonstrated. Key themes outlined for insight generation also include data source integration, open and constant dialogue between analysts and senior management plus some approaches and barriers to insight generation.
\end{abstract}

\section{INTRODUCTION}

It has been said that the quality of your life is in proportion to the quality of questions you ask. Imagine that in one part of a building, the senior managers are stressing over a big decision, but have no idea that in another part of the building vital and insightful information exists that will completely change the question driving the decision. The information resides in a combination of market research reports and the company's customer database.
What is concealing the information from the senior managers?

There are often structural and communications issues preventing such information flow. In his excellent paper, Steve Wills gives great experience-based advice on getting insights to the right people to ensure they are acted on. ${ }^{1}$ But, before communicating insights, how does a business generate them? Are some insights more powerful than others? When, where and how does data become information and some 
information become insightful? A vital part of the answer to these questions relates to where in the spectrum from tactics to company-wide strategy a business focuses its search for insights. But, first, one should be clear about what an insight is - and what it is not.

\section{WHAT IS AN INSIGHT?}

What is this catalytic, oft-sought business ingredient called an 'insight'?

Insights are new information giving you actionable ideas to drive your business in your stated desired direction and provide competitive advantage. ${ }^{2}$

This statement contains three important phrases: 'new information', 'actionable'; and 'stated desired direction'.

- New information: Any particular insight is not repeatable because an insight must be a new finding. One can't have the same insight twice or it is no longer new (unless you've a goldfish memory). For this reason, standard reports are not insights, nor are satisfaction surveys, product tacking studies or customer profiles. Reporting is applicable to established and familiar situations, whereas insights are new information. Companies should not call their data analysis areas 'customer insights' unless that is what the company (and the analysts) understand are required of them and are prepared to address the issues below to make them happen.

- Actionable: Information may be interesting, but this alone doesn't drive a business. What would need to be done differently to have information that clearly presents opportunities and competitive advantage, leading to management saying, 'That's new and I want to action it!'?
- Stated desired direction: To be an insight, a finding must also contribute to the organisation's goals, which typically include competitive advantage. The company's desired goals must be clearly articulated and fully appreciated by analysts (as well as those who request analysis). Without this clarity, isolated pieces of work often will not link easily together to illuminate the bigger picture. Tactical level analysis is all that is possible without clear, well articulated company direction.

A clear definition of 'insight', such as the one above, is needed so that analysts know what they are aiming to deliver. With businesses increasingly taking customer focus as their approach, insights about customers are vital to stay ahead of competitors. To be effective, the analyst is required to stand in the customer's shoes to think, feel and act like a customer, an aspect that analysts probably do not fully appreciate.

Insights may be the "flashes of inspiration or penetrating discoveries' that Steve Wills refers to. ${ }^{3}$ The manner of discovery may be more mundane, but just as powerful — this is discussed later in this paper.

Discovering an insight may be as simple as observing an unusual feature in the market and asking "Why does this happen?' The story of the Marriott hotel chain ${ }^{4}$ includes this type of insight. J. Willard Marriott, who founded the chain, started with food outlets in Washington DC in the 1920s. On a visit to his store near Hoover Airport he saw passengers en route to the airport stopping to pick up food for their flights. This struck him as extraordinary. Very rapidly he made arrangements to provide pre-packaged lunch boxes to Eastern Air Transport and other airlines. This was an opportunistic approach: he saw what 
people were doing, understood why and saw an opportunity. The act of noting the pre-flight passenger's behaviour is just information gathering, but Marriott asked why. He then had a big 'a-ha' moment when he realised what it would mean if his company provided the airlines with pre-packaged food. Insights come from asking the good questions - see later.

An insight may arise through something as simple as marrying together two data sources that had never shared a page before. Suddenly, a relationship between two facts is discovered that had not previously been appreciated leading, potentially, to new insights and actions. The possibly apocryphal story of the discovery of an increase in beer and nappy (diaper) sales on Friday nights, as father picked up the essentials on his way home from work, led to a supermarket placing these two items right next to each other, accelerating sales. ${ }^{5}$

An implication of these examples is that insights can arise from simple analysis. What counts more than the type of analysis is the thinking that leads to good questions that require analysis. This is discussed later in this paper.

\section{THE MARKET PICTURE}

Organisations always require a clear picture of the market and it is in the light of a current picture that insights are generated. An insight is new because it is not yet part of this picture. Once generated, insights enhance the picture by clarifying, providing new perspective and often simplifying the situation. The picture is the business's 'knowledge' and this should lead to market understanding. The insights generation area of a business needs to be an integral part of constantly building and increasing resolution of this picture, but ownership of the picture is best left with commercial areas.

Through the act of building and refining the picture, insights generation staff:

- Have a defined playing field with boundaries and clear goal area to aim for (the company's goals);

- Become aware of knowledge gaps, anomalies and other features that trigger good questions that may lead to insights; and

- Become familiar with the market place.

Part of the approach involves building higher levels of knowledge from basic data by integrating multiple sources. Knowledge constructed for a particular purpose, once fully understood, may be found to have an unforseen relationship with another area of knowledge; this is like the pillars of a building that need to be in place before the next floor can be built on top.

For example, understanding how purchase decisions are made may lead to the construction of one 'pillar of knowledge'. A second area of work, to predict customer response to different offerings, creates a second pillar of knowledge. Seeing how predicted customer response relates to how purchase decisions are made creates a higher level of knowledge formed by bridging these two knowledge pillars.

Integration of data sources is key to generating insights, and the market picture is clearer as a result. Data sources include any that could lead to insights, such as market research, database, competitor intelligence, customer surveys and integration with relevant external data sources. In this paper, the term 'data' refers to all such sources. Integration of multiple sources of information creates a much more powerful customer understanding than using a single source of information, typically bringing new opportunities to light. ${ }^{6-9}$ 
Information for marketing has two overall functions: understanding and implementation. Understanding includes understanding customers, the market and measurements - which all directly contribute to the market picture. Implementation includes positioning, planning the approach to market, campaign design, targeting, messages, timing and creative input - all of which are driven off information on the market picture.

\section{Analysis at strategic vs. tactical levels}

Strategy can be defined as a sustained pattern of resource allocation to meet pre-specified goals. To support this, marketing strategy is the approach used to allocate resources affecting which customers to target and what to offer. ${ }^{10}$

An insight at a strategic level can change an industry, but most marketers/ analysts are more micro-focused; insights at a tactical level are more typical and incremental advantages over competitors are the norm. An insight at the strategic level could, for example, lead to a new approach to market (eg a change from product focus to customer focus, by replacing the company-focused product profit-based segmentation with a customer needs-based segmentation) or the creation of a new category. It is better to create a category to be first in, than compete head-on. ${ }^{11}$ This is part of a brand strategy marketer's standard repertoire of approaches: change the game so we can play in a new space. The names of successful first-in-category products can become the category's household name, eg Xerox, Kleenex, Velcro, Band-Aid.

If tactically-focused analysis generates learnings, these are usually at the tactical level. If a range of offers are tested and one offer out-performs the others, then this can be applied immediately to the good of the business. For example, Capital One has a strategy of testing many offers, more than 30,000 a year. ${ }^{12}$ This approach results in a greater incremental advantage in targeting. The approach is a strategy, but the insights are largely at a tactical level - still powerful, but not leading to a new way of doing business. Alternatively, a new understanding of the customer can lead to a new approach to market, changing the whole market in the process

Databases support overall strategy in four types of activity across a broad range of industries (listed in decreasing frequency of use): customer retention, customer reactivation, product/service and promotion. ${ }^{13}$

Figure 1 illustrates the features described above.

A tactical focus lends itself to generating disconnected islands of knowledge (often very deep knowledge) that have less chance of leading to strategic insights because the islands of knowledge may be too far apart to make links between the islands.

In a company without clear and well communicated strategic direction, the analysis and research focus will inevitably be tactical and disjointed. Also, big picture insights, like recognising and defining new categories, will be infrequent.

Where, on the tactical-strategic spectrum, an organisation focuses any research and analysis can make a huge difference in the value gained from analysis. Figure 2 illustrates conceptually that a traditional approach to analysis (of any data source) will reach a certain rate of value growth to the company and then progress no further (it 'flatlines') as the focus is typically largely tactical. A balanced focus for analysis between stragegic and tactical levels can lead to an increased rate of growth in the value 


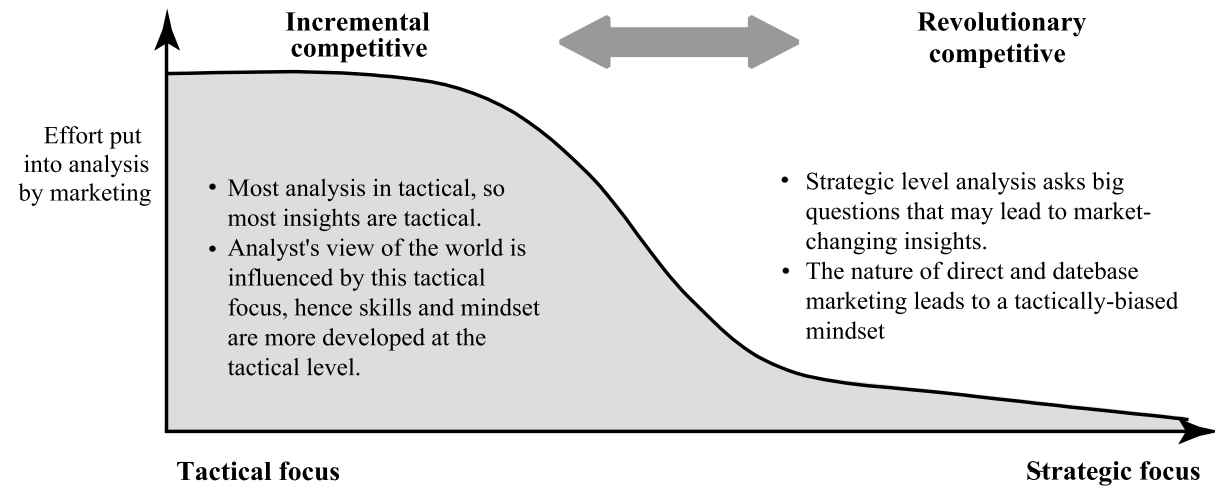

Figure 1: Tactically-focused analysis typically leads to incremental advantages, whereas revolutionary advantages can come from strategically-focused analysis.

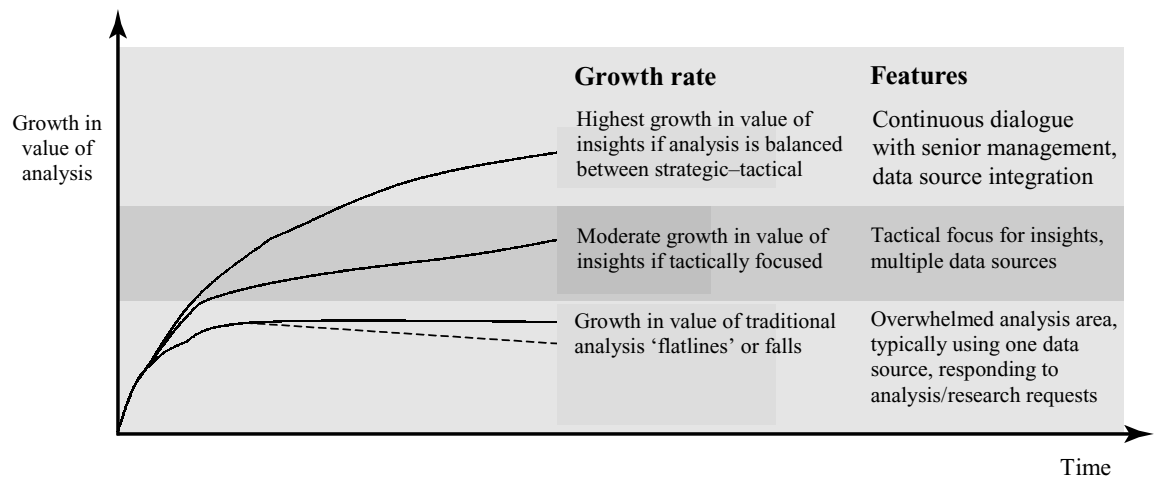

Figure 2: Traditional analysis approaches may deliver flat or even declining growth in value of analysis to the comapny wheras a balance between strategic and tactical levels can lead to an increase rate of growth in the value derived from analysis.

derived from analysis. Does the value from your research and analysis increase every year?

\section{Database and direct marketing are regarded as tactical}

Typically, market research, rather than the database, is the source of insights on the attitudes and needs of customers. ${ }^{14}$ Outside of organisations that have data as part of their business DNA, direct and database marketing are not on a CEO's radar for finding insights.

In developing and supporting corporate strategy, many organisations do not realise the full potential of customer databases nor integrate them with other sources, such as market research. ${ }^{15}$

Reasons for this include:

- The brand's positioning and resulting communications strategy dictate most marketing activities, including direct and database marketing. This means that direct and database marketing are correctly regarded as relatively tactical. Brand strategy gets board level attention, while anything to do with database or direct marketing may not get such visibility. The insights that can be gained from a database - especially when combined with other sources should be important inputs to strategic decisions and a key part in 
establishing metrics to measure the implementation of the strategy.

- The lack of an overall, coherent strategic role of direct and database marketing relegates the entire activity to a lower level of expectation in an organisation. ${ }^{16}$ The impact of this, especially outside of organisations where data is the core of the business, includes the assumption that direct and database marketing are tactical tools, the development of a mind-set among such marketers and analysts that largely excludes strategic possibilities (in contrast to brand-strategy marketers ${ }^{17}$ ), the exclusion of such marketers and analysts from high-level decisions and a consequent loss of potential resources and influence for direct and database marketing.

- Most data collected relates to tactics, with the exception of some market research and competitor intelligence. Data related to tactics tends to be used (if used at all) in connection with tactics, such as pre- or post-product launch comparisons of shifts in consumer attitudes or campaign tracking.

Data and databases can be heavy subjects, less amenable than visual aspects of brand campaigns. It takes strong communications skills to explain data-driven opportunities, but analysts are not usually recruited with this as a key requirement. In many businesses, the commercial people asking business questions are at a remove from the information that could address their questions. The information is not easily accessible or is too complex.

Analysis departments are typically overwhelmed, leaving little time for standing back and asking good questions. The value of these departments is viewed in terms of output, but the output is determined by the requests they act on, typically tactical. This point and the previous point concerning their being overwhelmed can lead to a vicious circle: a tactically focused analysis request, possibly not clearly thought out or explained, adds to the overload of the analysis department and leads it to delivering the bare minimum. There is no time for considering the meaning and implications of the information generated, hence no insights, leading to a low value being put on the analysis area. Typically, analysis areas answer other people's questions. By proactively engaging the commercial areas and posing good questions the credibility of analysis areas will be raised.

Approaches demanding integration of database and market research are not frequent enough, either in terms of analysis or for campaign use, to make integration of these types of areas commonplace. Greater integration of databases with other information sources, especially market research, is one opportunity to contribute more and raise the visible value of a database.

\section{FINDING INSIGHTS}

Finding significant insights in part relates to finding the appropriate balance of focus between tactical and strategic levels, as described above. Some other practical learnings are discussed below.

\section{Senior dialogue}

An insights area can make great headway if it can establish an open and constant dialogue between analysts and senior management. This enables incomplete ideas and rough solutions to pass back and forth in a more informal and creative manner than traditional formal requests with full delivery of work and limited discussion. This extends to 
proactive partnering with the all relevant stakeholders, as insights can be increasingly generated in new interactions between staff from different areas. Proactive partnering includes making it possible for analysts to be part of early client planning so opportunities can be spotted from the start.

\section{Ask good questions}

All insights analysis starts with asking good questions of the 'What if?' hypothesis-driven type. These questions apply across multiple data sources and the answers must be explanations with consideration of the implications, not just descriptions. Good questions take account of the big picture and people can be expected to respond with: 'I never thought of it that way'

The mindset of a person asking good questions is in part due to reflexively responding to situations with questions rather than statements. When confronted with a situation, note if you react with a statement as part of your internal dialogue or with a question. For example, if poor sales results unexpectedly arise, some people will be obsessed with how bad the news is while others will ask 'Why and how did this happen?' and this leads to solutions, even insights.

Typically, not many people can address these questions effectively since few have enough understanding of the diversity of information and a solid market understanding (see previous section). It can help to establish a taxonomy of questions so that the categories of questions being asked (and not asked) become apparent, provided this is not used as a rigid formula. For example, a topic in the taxonomy may be: 'How do I assess the value of customers?' This breaks down into many further questions that attempt to address this, such as:
- How do I define value?

- Is this in terms of revenue, profit or a measure of the referred business they bring? What is the Pareto ratio? (the few customers generating most value?)

- Can I predict who will remain a customer - for how long?

- How do I estimate a customer's individual future potential? How do I know when I've increased it?

These questions reflect the following categories of ideas in the taxonomy: definitions (eg 'How do I define value?', typically starting with a broader concept that is then refined to be specific); mechanics ('Once I've settled on a definition, how do I implement it?'); immediate implications ('Where does most of the value come from?' 'What is the Pareto ratio'); future implications for further opportunities (the initial answers take you to a new level of understanding that generate further insights and more questions).

The literature includes may ways of encouraging the development of good questions, ${ }^{18,19}$ such as playing Devil's advocate, the view from the customer's shoes, reverse engineering ideal situations to see how they could be made to occur or examining the polar extremes of the implications of an argument.

\section{What to focus on?}

The question of what to focus on for maximum effect depends on individual circumstances, particularly the key problems that an organisation needs to address. Within these priorities, balancing strategic and tactical focus, by building the market picture, new understanding and some insights will come from identifying the following:

- Anomalies or unusual features brought out from the data, eg the Marriott 
in-flight catering story ${ }^{20}$ outlined above.

- Conflicting or contradictory information, eg 'Why is our market share almost as big at non-target malls as at targeted malls?'

- Gaps in market understanding will raise important questions - 'Why does this happen?' - that will initiate new insightful analysis.

- Assumptions, business rules and definitions: challenging assumptions and critiquing definitions or business rules is a fertile area that leads to new views on the market and insights.

In doing the above, linking data sources in a way not done previously will lead to new relationships being recognised (eg the beer and nappies example). ${ }^{21}$

\section{Data integration and growth}

Since data integration has been established to be a key requirement, mechanisms for achieving this are required. This does not necessarily require heavy technical solutions to consolidate disparate data; technology cannot generate insights, people do. Each separate source of data has to be healthy enough for the purpose required. A key question to consider is, "How much does a particular investment in technology contribute to relevant market knowledge and insights?'

Centralisation of the insights analyst area has many advantages, but careful management is required to ensure it works. Centralisation of analysts does not necessarily require centralising and consolidating the data, but ease of access to data sources is critical. An approach to developing the company's knowledge base as an asset, including how to increase its value, needs to be in place.

Further, Stone et al. ${ }^{22}$ discuss methodology for assessing the quality of customer information management in customer life cycle management. This can show where an organisation is strong or weak in acquisition and use of customer information, although value of insights is not specifically included in the methodology.

Davenport ${ }^{23}$ provides a useful collection of examples of what companies like Amazon, Capital One, UPS, Marriott and P\&G are doing by taking advantage of analysing integrated information, although he focuses on 'what' they are doing, not 'why' they focus on certain chosen areas of analysis. Only limited one-off advantages will be gained if this is regarded as just a matter of operational excellence.

\section{IMPLICATIONS}

The implications of the above for a business, beyond realistic resourcing and setting expectations, are that:

- Tenacity is required. Management asks for insights, insights are new information and people are often resistant to new ideas. Analysts and marketers should use pre-selling of ideas to key stakeholders to avoid a backlash from insights that management don't believe in or don't like. Stakeholders will ask for work all to be repeated, question assumptions, question why something more useful hasn't been done and reject the implications. Analysts and marketers should not easily be put off?

- Management should trust that the insights area will deliver value; this can take time. Exploring areas currently critical to the business, such as how the next product launch can be enhanced, can give quick visible wins. Almost any well thought-out analysis work will contribute to building the market picture, even if it 
does not lead to insights. The 'senior dialogue' mentioned above also helps.

- Recruiting technically capable analysts is not enough. They must be commercially aware, capable communicators and insanely curious so that they keep asking many questions.

- Communication of insights is as important as insights generation see Wills for suggestions on how to achieve this. ${ }^{24}$

- Managers of research and analysis must drive the need and opportunity to ask many good questions, but should focus the topics where the business most needs them.

Management must also defend their staff from being overloaded with analysis requests. $3 \mathrm{M}$ has a policy of giving staff 15 per cent of their time to work on projects of their own, provided they meet certain criteria. ${ }^{25}$

- Data should be put in the hands of those that need it, via user-friendly tools and good basic reporting. A report generation and maintenance area should be responsible for this. Separate out the insights area from reporting, as the mind-set required is utterly different and will sidetrack analysts into a mire of work that cannot generate insights. Create a central point for all data-related requests, be it for market research, database etc.

\section{CONCLUSIONS}

There's a lot more to a successful business than insights. Areas like manufacturing, sales and distribution have already benefited from intense competition, but competitors can copy almost any product or service rapidly. Innovation as a process is much harder to copy. Insights form the basis for innovations so, in the areas of sales and marketing, developing an accelerating insights engine is an essential part of accelerated success.

A clear, common understanding of what an insight is helps a business focus on generating them. Asking good questions and knowing where to focus, plus integrating data sources are key to generating insights. Once an insight is generated, Wills clearly shows that it has to engage the persons who can take actions based on it to realise its value. ${ }^{27}$

Finding significant insights in part relates to finding the appropriate balance of analytical focus between tactical and strategic levels. For strategic insight generation, an open and constant dialogue between analysts and senior management is more effective than traditional formal requests with full delivery of work and limited discussion. Tactical level analysis is all that is possible without clear company direction. Tactical focus is more likely to result in tactical level insights and disconnected islands of knowledge that add limited clarity to the market picture.

The insights area should be separated from the reporting area as the mind-set required is utterly different. Put basic data in the hands of those that need it to take the burden of basic analysis requests away.

Even if direct and database marketing are regarded tactically, the insights that can be gained from a database especially when combined with other sources - should be important input to strategic decisions.

\section{References}

1 Wills, S. (2005) 'The management and communication of customer insight', Journal of Interactive Marketing, Vol. 6, No. 4, pp. 302-316.

2 Author's definition.

3 Wills (2005) op. cit.

4 Collins, J. and Porras, J. (1994) Built to Last, Harper Collins, New York, NY.

5 Anon. (1997) 'Beer and nappies — A data mining urban legend', Available at: http://web.onetel.net.uk/ hibou/Beer\%20and 
\%20Nappies.html, last accessed 3 July, 2006.

6 Wills (2005) op. cit.

7 Mouncey, P., Tzokas, N., Hart, S. and Roslender, R. (2002) 'Core strategic asset or just a tactical tool: How UK companies view the value of their customer databases', Journal of Interactive Marketing, Vol. 4, No. 1, pp. 41-58.

8 Heuer, R. (1999) 'Keeping an open mind', Chapter 6 in Psychology of intelligence analysis by the Center for the Study of Intelligence, The Central Intelligence Agency (USA). Available at: http://www.cia.gov/csi/books/19104/art9.html .

9 Cooper, T. and Goulds, A. (2001) 'The marriage of market research and database marketing: A case study illustrating an integration process and how success can be achieved', Journal of Database Marketing \& Customer Strategy Management, Vol. 8, No. 2, pp. 150-156.

10 Smith, B. (2002) Out of your Comfort Zone Why Pharmaceutical Marketing Strategies are Weak, PML Publications (published on www.pmlive.com), last accessed 3 July, 2006.

11 Ries, A. and Trout, J. (1993) The 22 Immutable Laws of Marketing, Harper Business, New York, NY.

12 Davenport, T.H. (2006) 'Competing on analytics', Harvard Business Review, Vol. 84, No. 1, pp. 99-107.
13 McClymont, H. and Jocumsen, G. (2003) 'How to implement marketing strategies using database approaches', Journal of Database Marketing \& Customer Strategy Management, Vol. 11, No. 2, pp. 135-148.

14 Mouncey et al. (2002) op. cit.

15 Mouncey et al. (2002) ibid.

16 Tapp, A. (2002) 'The strategic value of direct marketing: Expanding its role within the company', Journal of Database Marketing \& Customer Strategy Management, Vol. 9, No. 2, pp. 105-112.

17 Aaker, D. and Joachimsthaler, E. (2000) Brand Leadership, Simon \& Schuster, New York, NY.

18 Heuer (1999) op. cit.

19 Osborn, A. (1953) Applied Imagination, Schribners, New York, NY.

20 Collins \& Porras (1995) op. cit.

21 Anon (1997) op. cit.

22 Stone, M., Foss, B., Henderson, I. et al. (2003) 'The quality of customer information management in customer life cycle management', Journal of Database Marketing \& Customer Strategy Management, Vol. 10, No. 3, pp. 240-254.

23 Davenport (2006) op. cit.

24 Wills (2005) op. cit.

25 Tapp (2002) op. cit.

26 Wills (2005) op. cit. 